\title{
Batteries show the difficulties of being greener
}

\author{
Proposed new regulations for the European battery industry could end up making the electrification of transport \\ harder - and reveal the complexity of creating sustainable markets.
}

W ith climate change firmly and urgently on the global agenda, there is plenty of discussion about how to regulate industries to reduce their carbon footprint. That debate is particularly intense in the transport sector, where electrification is becoming a priority. The European Union (EU), for example, is planning to require that all new cars sold from 2035 have zero carbon emissions a bold and valuable goal, but one that will demand the rapid development of both vehicle-charging infrastructure and battery production. At the same time, the EU has proposed new regulations on battery technologies that aim to also make the industry more sustainable and less polluting. These goals are laudable, but not everyone is persuaded that they add up to a coherent strategy.

Last July, a team of experts in climate policy and materials use argued that the new EU battery regulations might have unintended consequences that could end up undermining climate-change mitigation targets (H. E. Melin et al. Science 373, 384-387; 2021). At root, the problems are those that have always been central to capitalistic economies: how to find the right balance between regulation and the freedoms that enable companies to innovate, to find creative solutions and to be competitive. Balancing that equation is rarely simple; in this case, with its complex interweaving of supply chains and other industry requirements and with carbon footprints to consider at every step, the issues are particularly fraught.

For vehicle electrification, lithium-ion batteries are the key energy technology. Making this battery technology more sustainable demands a consideration of the environmental and economic costs of extraction and transport of raw materials, manufacture, and increasingly of materials recycling and reuse at the end of a battery's life. The proposed new EU regulations, which may come into force in 2023 and will update the 2006 EU Battery Directive, seek to make all of these considerations comply with strict standards geared towards minimizing the costs to the environment. The regulations will constrain not only battery manufacturers within Europe but

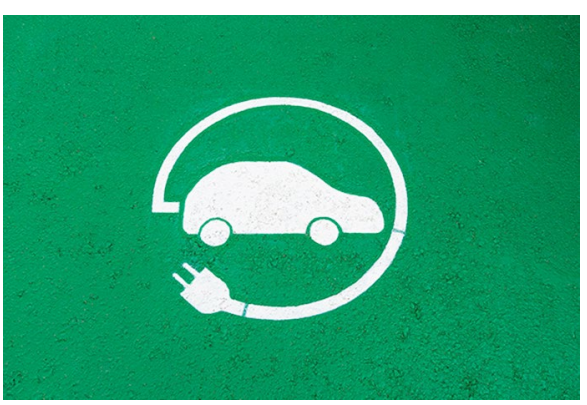

Credit: Jurgita Vaicikeviciene / Alamy Stock Photo

also electric-vehicle companies, who will need to source their batteries in ways that meet the regulations.

But here's the problem: Europe is not especially well situated to optimize compliance with the new demands. It does not, for example, have a strong domestic market for lithium: global supplies of the metal come mostly from Australia, Chile and China. Portugal is the only substantial European source, but its annual production is barely $4 \%$ of that of Australia. So battery companies will need to ensure that their raw materials are produced in ways that meet the standards even though the key suppliers are not themselves bound by EU laws.

Electric-vehicle companies might well find, especially given these constraints on local manufacturers, that they can procure batteries more cheaply from outside the $\mathrm{EU}$ - it could be hard for European battery manufacturers (and producers of related components) to compete. Needless to say, long-distance imports incur a carbon-footprint penalty. Suppliers outside the EU will also need to meet the EU standards if they are going to sell to that market - but they may be better placed to do so in, say, China, where the battery industry is already more mature, including the capacity for recycling.

The irony is that by placing stringent regulations on the still-emerging battery and electric-vehicle industries to enforce the desirable goal of making them more environmentally friendly, they might end up having to cope with more challenging constraints than the existing transportation industries relying on fossil fuels. This would make it harder for such green technologies to compete, and also to innovate. It can end up making more economic sense to find ways round the regulations rather than to comply with them - for example, to look for different raw materials or to make different products (such as lower-capacity batteries) that are not subject to all the supply-chain and recycling requirements. That's reminiscent of the familiar loophole with decarbonization and anti-pollution regulations: companies might simply outsource rather than address the problems the rules seek to tackle. It's what has become known in artificial-intelligence research as a perverse instantiation: you stipulate a goal, but find it being met in ways you neither anticipated nor wanted.

The bottom line is that if you want an industry or a technology to grow, you generally have to allow it some latitude in the early days. Excessively rigid restrictions on how it may operate can stifle its ability to adapt and compete. Holding European battery manufacturers to high standards is a noble aim, but becomes self-defeating if it sets the bar too high for them to compete in the global marketplace. What's more, battery technology is itself still in flux, and a suite of carefully constructed regulations on materials is pointless if technical advances quickly render them obsolete.

The problems are not insoluble, though, nor do they require a capitulation to a dangerous laissez-faire. They need joined-up thinking, including consideration and perhaps modelling of what the broader knock-on effects of regulations might be. But - and this doubtless applies more generally to regulations intended to mitigate climate change - they might also require new models of how to regulate, which allow for flexibility and adaptation to changing demands and technologies, and judicious incentives for compliance, and which make optimal use of the increasing body of global data on materials supply chains and reuse and their carbon costs.

Published online: 2 February 2022 https://doi.org/10.1038/s41563-022-01198-1 